\title{
Synthesis, Characterization, and Evaluation of Antimicrobial Activities of Chitosan and Carboxymethyl Chitosan Schiff-Base/Silver Nanoparticles
}

\author{
Ahmed M. Khalil, ${ }^{1}$ Reham A. Abdel-Monem, ${ }^{1}$ Osama M. Darwesh, ${ }^{2}$ Ahmed I. Hashim, ${ }^{3}$ \\ Afaf A. Nada, ${ }^{1}$ and Samira T. Rabie ${ }^{1}$ \\ ${ }^{1}$ Photochemistry Department, National Research Centre, El Buhouth St., Dokki, Giza 12622, Egypt \\ ${ }^{2}$ Environmental Biotechnology and Nanotechnology, Agricultural Microbiology Department, National Research Centre, \\ El Buhouth St., Dokki, Giza 12622, Egypt \\ ${ }^{3}$ Chemistry Department, Faculty of Science, Ain Shams University, Cairo, Egypt
}

Correspondence should be addressed to Ahmed M. Khalil; akhalil75@yahoo.com

Received 23 October 2016; Accepted 26 December 2016; Published 15 March 2017

Academic Editor: Francisco Javier Deive

Copyright (c) 2017 Ahmed M. Khalil et al. This is an open access article distributed under the Creative Commons Attribution License, which permits unrestricted use, distribution, and reproduction in any medium, provided the original work is properly cited.

Schiff-bases of chitosan (CS) and carboxymethyl chitosan (CMCS)/silver nanoparticles (AgNPs) have been synthesized, characterized, and evaluated as antimicrobial agents against two Gram +ve bacteria (Bacillus cereus and Staphylococcus aureus) and two Gram -ve bacteria (Escherichia coli and Pseudomonas aeruginosa) in addition to Candida albicans as a fungus. The in situ reactions of CS and/or CMCS with some pyrazole aldehyde derivatives in acidic media containing silver nitrate to yield silver nanoparticles loaded onto CS and CMCS/Schiff-bases were carried out. Characterizations of the prepared compounds via FTIR spectroscopy, SEM, TEM, and TGA were carried out. Schiff-bases/silver nanoparticles of CS and CMCS showed higher antimicrobial activity than the blank CS and CMCS. The presence of $\mathrm{AgNO}_{3}(3 \% \mathrm{wt} \%)$ displayed high antibacterial efficiencies with inhibition zones in the extent of 19-39 mm. TEM analysis showed that the size of the silver nanoparticles is in the range of 4-28 $\mathrm{nm}$ for the prepared nanocomposites.

\section{Introduction}

The natural-based biopolymer chitosan derived from chitin can be considered as the second most abundant natural polymer next to cellulose [1]. Chitosan as a chitin derivative can be obtained by the $\mathrm{N}$-deacetylation process, resulting in the amino group at C-2 position on its backbone. Both chitin and chitosan are considered as naturally occurring polysaccharides with commercial interest because of their great nitrogen content $(89.6 \%)[2-4]$.

Chitosan can be used as a biomaterial due to its biocompatibility, biodegradability, bioactivity, and low effect of toxicity. This approach has promoted chitosan to be employed in medical [5], pharmaceutical, agricultural, and environmental fields [6, 7]. In addition, chitosan can be used in the packaging domain due to its high efficiency in inhibiting spoilage by killing pathogenic microorganisms that contaminate food [8]. The antimicrobial activity of chitosan can be attributed to the basic nature of the polymer and its amine content. Chitosan can bind and disrupt the normal functions for the membrane of bacteria by promoting the leakage of intracellular components and inhibiting the transport of nutrients into the cells [9-11]. Previous works have focused on the effects of molecular weight and the degree of deacetylation of chitosan on some antibacterial and antifungal activities [12-15].

Chitosan molecule bears free amino groups at C-2 position which can allow chemical substitution reactions to get various derivatives [16, 17]. Among these derivatives, chitosan Schiff-base can be obtained by the reaction of these free amino groups of chitosan with active carbonyl compounds such as aldehyde or ketone $[18,19]$ with the created 
imine group $(-\mathrm{RC}=\mathrm{N}-)$ on the Schiff-base product [20]. Some chitosan Schiff-bases are reported to be more potent antimicrobial agents than chitosan [21-23].

Carboxymethyl chitosan (CMCS) exceeds chitosan in its solubility in water. CMCS is highly viscous, biodegradable, biocompatible, and nontoxic and is able to form films, fibers, and hydrogels $[24,25]$ acting as a bactericide, a moisture-retention agent, artificial bone and skin, wound dressing agent, and blood anticoagulant and can contribute in drug delivery matrices [26]. Schiff-base derivatives of carboxymethyl chitosan were synthesized by their reactions with different aldehydes as para-substituted benzaldehydes. Antibacterial activities of the Schiff-bases against Escherichia coli and Staphylococcus aureus were evaluated using the optical density method. Antibacterial efficiency of the Schiff-base may vary according to the substituent at the para-position of the aldehyde. This efficiency increases as the electron donating potency increases [27]. Eighteen carboxymethyl chitosan (CMCS) Schiff-bases and their reduced derivatives have been synthesized and tested against various types of Gram +ve and Gram -ve bacteria and Aspergillus fumigates, Geotrichum candidum, and Candida albicans as fungi [28].

Recently, it is well known that nanoparticles are considered to be viable alternatives to antibiotics and seem to have an effective potency to solve the problem of the emergence of bacterial multidrug resistance [29-32]. In the past, silver was used as an antiseptic and antimicrobial agent against Gram +ve and Gram -ve bacteria $[33,34]$ due to its low cytotoxicity [35]. Recently, silver nanoparticles are used to produce of a new class of antimicrobials [36-38] opening up a completely new way to withstand a wide range of bacterial pathogens. Although the high antibacterial activity of AgNPs has been widely described, their actions are yet to be fully elucidated.

This study is concerned with the synthesis, characterization, and evaluation of some Schiff- bases of chitosan and carboxymethyl chitosan via condensation with some pyrazole aldehyde derivatives in the presence of AgNPs to investigate their antimicrobial activities.

\section{Experimental}

2.1. Materials. Low molecular weight chitosan with $82 \%$ degree of deacetylation was obtained from Funakoshi Co., Ltd, Japan. All chemicals are of fine grades and all solvents are distilled before use.

\subsection{Methods}

2.2.1. Preparation of Carboxymethyl Chitosan (CMCS). Carboxymethyl chitosan, CMCS, was prepared according to the previously described method [39]. Chitosan (10 g), sodium hydroxide $(13.5 \mathrm{~g})$, and solvent isopropanol $(100 \mathrm{~mL})$ were suspended in a flask to swell and alkalize at room temperature for $1 \mathrm{~h}$. The monochloroacetic acid $(15 \mathrm{~g})$ was dissolved in isopropanol and added to the reaction mixture drop-wisely within $30 \mathrm{~min}$ and reacted for $4 \mathrm{~h}$ at $55^{\circ} \mathrm{C}$. Then the reaction was stopped and isopropanol was discarded. Ethyl alcohol $(80 \%)$ was added and the solid product was filtered and rinsed with $80 \%$ ethyl alcohol to desalt and dewater and then vacuum dried at $50-81^{\circ} \mathrm{C}$. The degree of substitution of carboxymethyl chitosan was determined by $\mathrm{pH}$ titration and found to be 0.75 .

\subsubsection{Synthesis of Chitosan/Pyrazole-Schiff-Base Loaded with} Silver. Chitosan or carboxymethyl chitosan $(0.1$ moles) with the following weight: $0.161 \mathrm{~g}$ or $0.219 \mathrm{~g}$, respectively, was dissolved in $1 \%$ acetic acid. Equimolar amount of each aldehyde was added to the above solution in absence and in presence of silver nitrate $(1,2$, and $3 \%$ weight ratio). The reaction mixture was stirred for $6 \mathrm{~h}$ at room temperature, then poured into ethanol, boiled, and finally left overnight to collect the solid product.

Scheme 1 represents the reaction of CS and/or CMCS, $\mathbf{a}$ and $\mathbf{b}$, respectively, with the pyrazole aldehydes $(\mathbf{c}-\mathbf{f})$ that are represented in Scheme 2. Table 1 shows the eight CS and CMCS Schiff-base derivatives which are obtained with their melting points, colors, and yields\%. Compounds 1, 3, 5, and 7 are Schiff-bases of CS, whereas compounds $\mathbf{2 , 4 , 6}$, and 8 are Schiff-bases of CMCS.

2.2.3. FTIR Spectroscopy. FTIR spectra were recorded on Shimadzu IR-Spectrometer (FTIR 8201) Japan, at room temperature within the wavenumber range of 4000 to $400 \mathrm{~cm}^{-1}$ using $\mathrm{KBr}$ discs.

2.2.4. Scanning Electronic Microscopy (SEM). The dry samples were spread on a conducting adhesive tape, pasted on a metallic stub. The morphologies of the tested samples were investigated and imaged with scanning electron microscope (SEM) (QUANTA FEG 250 ESEM, USA). This was accompanied by energy dispersive X-ray spectroscopy (EDAX AMETEK Inc.; Mahwah, NJ, USA) at an acceleration voltage of $15 \mathrm{kV}$. The films were fixed on the surface of a sticky tape.

2.2.5. Transmission Electron Microscopy (TEM). Micrographs of the colloidal particles were taken using JEOL JEM-2100 (JEOL, Japan), of $200 \mathrm{kV}$ with magnification range from $1000 \mathrm{x}$ to $50000 \mathrm{x}$. The TEM samples were prepared and placed on a copper grid by mixing one dilute drop of prepared aqueous particles dispersed in $5 \mathrm{~mL}$ acetone to become slightly turbid solution and allowing it to dry well. The images of representative areas were captured at suitable magnifications which clarify the morphology and the size of the nanoparticles.

2.2.6. Thermogravimetric Analysis (TGA). Thermogravimetric analysis was carried out on TGA-50H thermogravimetric analyzer, Shimadzu, Japan. Samples were heated up to $800^{\circ} \mathrm{C}$ in a platinum pan with a heating rate of $10^{\circ} \mathrm{C} / \mathrm{min}$, in $\mathrm{N}_{2}$ atmosphere of flow rate $25 \mathrm{~mL} / \mathrm{min}$.

2.2.7. Pathogenic Strains. Pathogenic microorganisms used in this study were obtained from the American Type Culture Collection (ATCC; Rockville, MD, USA) and National Research Centre (NRC), Egypt. Two Gram +ve bacteria and 


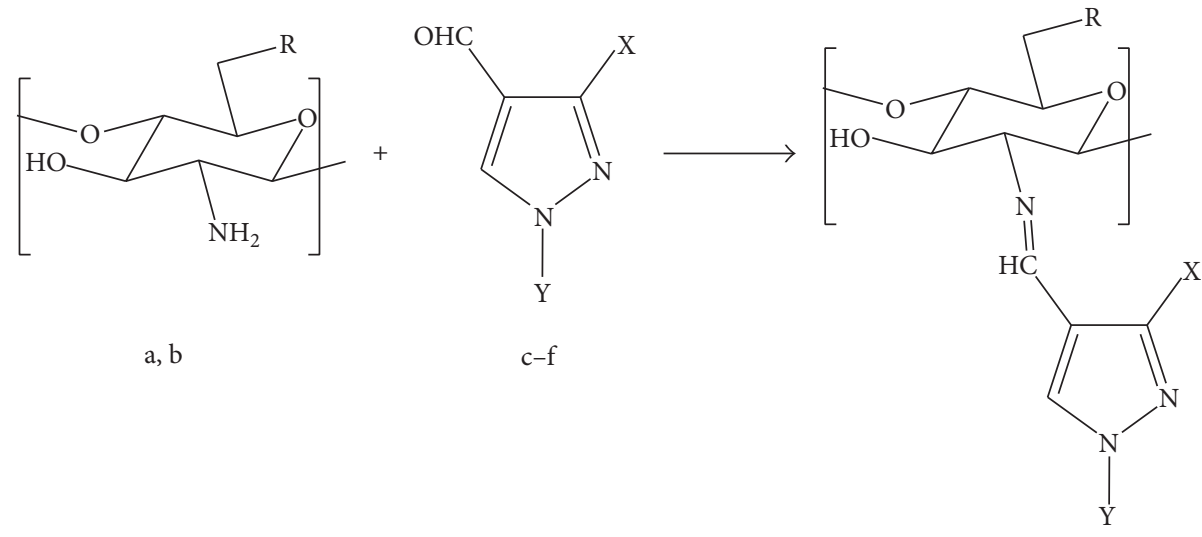

$1-8$

SCHEME 1: Reaction of CS or CMCS with pyrazole aldehydes. $\mathbf{a}: \mathrm{R}=\mathrm{OH}(\mathrm{CS})$. $\mathbf{b}: \mathrm{R}=\mathrm{OCH}_{2} \mathrm{COOH}(\mathrm{CMCS})$.

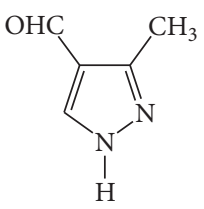

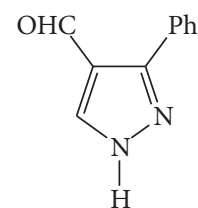

d

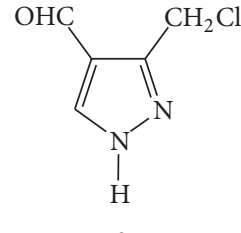<smiles>O=Cc1cn(-c2ccccc2)nc1-c1ccccc1</smiles>

f

Scheme 2: Chemical structures of pyrazole aldehydes: c: 3-methyl- $1 H$-pyrazole-4-carbaldehyde; d: 3-phenyl- $1 H$-pyrazole-4-carbaldehyde; e: 3-chloromethyl-1H-pyrazole-4-carbaldehyde; f: 1,3diphenyl-1H-pyrazole-4-carbaldehyde.

two Gram -ve bacteria as well as a fungus were used. The pathogenic microorganisms subjected for this study were Bacillus cereus (B. cereus) ATCC-12228 and Staphylococcus aureus (S. aureus) ATCC-47077 as Gram +ve bacteria and Escherichia coli (E. coli) ATCC-25922 and Pseudomonas aeruginosa strain (P. Aeruginosa strain) OS4 as Gram -ve bacteria beside Candida albicans (C. albicans) ATCC-10231 as a fungus.

2.2.8. Antimicrobial Activities. The antimicrobial activities of chitosan modified compounds were assayed by agar wells diffusion technique. Agar plates were prepared using nutrient agar for bacteria while potato dextrose agar was applied for fungi. The plates were inoculated with $0.1 \mathrm{~mL}$ containing $10^{6} \mathrm{cfu} / \mathrm{mL}$ of fresh bacterial cultures and spore suspensions of pathogenic strains. Wells of $7 \mathrm{~mm}$ in diameter were dug on the inoculated agar plates using a sterile cork borer in solidified agar. The tested compounds prepared in DMSO $(60 \mu \mathrm{L})$ were added to the wells. DMSO as dissolving agent was tested as control [40]. Plates were left for two hours at $4^{\circ} \mathrm{C}$ (in the refrigerator) to allow the diffusion and then incubated for $24 \mathrm{~h}$ at $37^{\circ} \mathrm{C}$ for bacteria, while fungi plates were inoculated at $28^{\circ} \mathrm{C}$ for $72 \mathrm{~h}$. The antimicrobial activities of tested compounds were determined by measuring the three replicates of the inhibition zones around the well $[41,42]$.

\section{Results and Discussion}

Schiff-base compounds with an imine group are usually formed by the condensation of a primary amine with an active carbonyl group. Also they have better physiological activities and applications in antibacterial and antiviral fields [43]. Among the substituted biopolymers, particularly noteworthy are the Schiff-bases obtained by the reactions of the free amino groups of chitosan with an active carbonyl compound such as aldehyde or ketone [44].

3.1. Synthesis of CS and CMCS/Schiff-Base Silver Nanoparticles. Chitosan and carboxymethyl chitosan/Schiff-base loaded with silver nanoparticles was synthesized as described in the experimental part. The incorporation of silver nanoparticles into the chitosan and carboxymethyl chitosan/Schiff-base chains was attained via the reduction of the $\mathrm{AgNO}_{3}$ salt.

FTIR spectra of CS, CMCS, and their pyrazole derivatives Schiff-base show IR absorption peaks ranging from 3413 to $3436 \mathrm{~cm}^{-1}$ (for different derivatives) which are corresponding to the $-\mathrm{OH}$ and $\mathrm{NH}_{2}$ groups stretching vibration in $\mathrm{CS}$ and CMCS in addition to the intermolecular hydrogen bonds of the polysaccharide [45]. The observed IR absorption peak at ranges of $1582-1607 \mathrm{~cm}^{-1}$ represents the imine group $-\mathrm{CH}=\mathrm{N}-$ in different formed Schiff-base derivatives, which is not a characterizing one for neither CS nor CMCS. Figures 1(a) and 1(b) demonstrate the FTIR spectral analyses of chitosan and carboxymethyl chitosan/pyrazole Schiff-base derivative 3. The IR absorption band appearing at $1598 \mathrm{~cm}^{-1}$ in Figure 1(b) emphasizes the formation of the imine group, $-\mathrm{CH}=\mathrm{N}-$, in chitosan/Schiff-base. Table 2 shows the absorption IR peaks of the imine groups of the different formed chitosan and carboxymethyl chitosan/pyrazole Schiff-base derivatives. 
TABLE 1: Chemical structures, mp, yield\%, and elemental analysis of CS or CMCS/Schiff-bases.

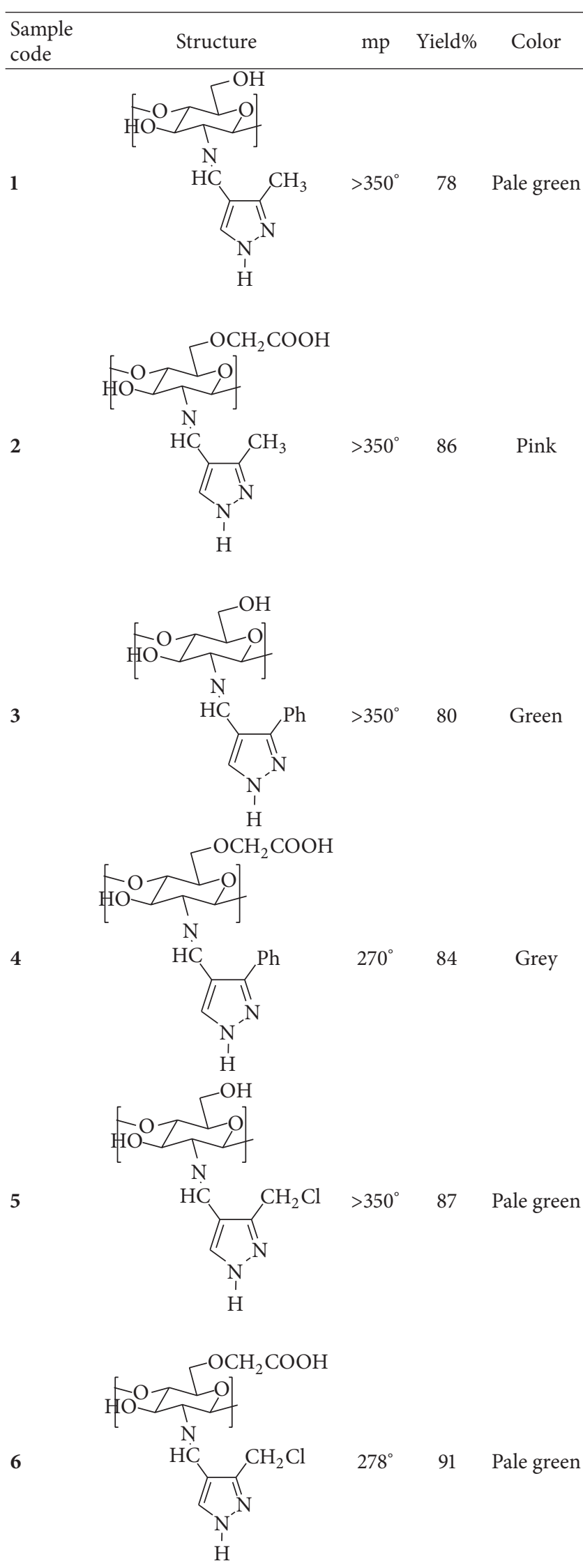

TABLE 1: Continued.

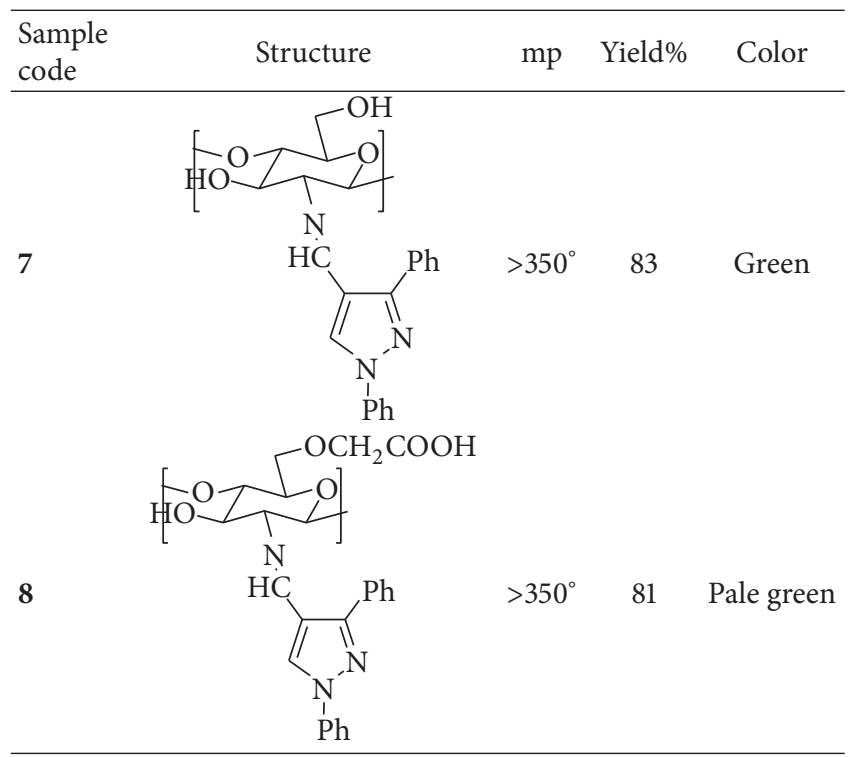

TABLE 2: FTIR peaks of the imine group for different CS or CMCS/Schiff-bases.

\begin{tabular}{lccc}
\hline $\begin{array}{l}\text { Sample } \\
\text { code }\end{array}$ & $\begin{array}{c}\text { IR peak, } v, \mathrm{~cm}^{-1} \\
\text { (for -C=N group) }\end{array}$ & $\begin{array}{c}\text { Sample } \\
\text { code }\end{array}$ & $\begin{array}{c}\text { IR peak, } v, \mathrm{~cm}^{-1} \\
\text { (for }-\mathrm{C}=\mathrm{N} \text { group) }\end{array}$ \\
\hline CS & null & CMCS & null \\
1 & 1607 & 2 & 1602 \\
3 & 1598 & 4 & 1602 \\
5 & 1600 & 6 & 1626 \\
7 & 1582 & 8 & 1595 \\
\hline
\end{tabular}

3.2. Scanning Electron Microscopy (SEM). The SEM micrograph for chitosan nanocomposite with 3-methyl-1Hpyrazole-4-carbaldehyde loaded with silver nanoparticles (AgNPs) is represented in Figure 2(a). The surface seems to be porous with some inclusions. The presence of silver nanoparticles is noticed to be with homogenous distribution on the surface of the matrix. Similar appearance is shown in Figure 2(b) for chitosan with silver nanoparticles, but with higher particle size which is elucidated by TEM technique. The increase in size may be due to the existence of 1,3diphenyl-1H-pyrazole-4-carbaldehyde in the investigated nanocomposite. Rough surface appearance is observed for the surface morphology of carboxymethyl chitosan in the presence of 3-methyl-1H-pyrazole-4-carbaldehyde. AgNPs are well distributed through the whole matrix as illustrated in Figure 2(c). Less cavities for the surface of carboxymethyl chitosan are noticed with some roughness in Figure 2(d). This may be due to 1,3-diphenyl-1H-pyrazole-4-carbaldehyde providing more uniformity and consistency for the structure of carboxymethyl chitosan with developing the structure of the spherically formed silver nanoparticles.

3.3. Transmission Electron Microscopy (TEM). Figure 3(a) illustrates the TEM micrograph for the nanocomposite of chitosan/3-methyl-1H-pyrazole-4-carbaldehyde loaded with 


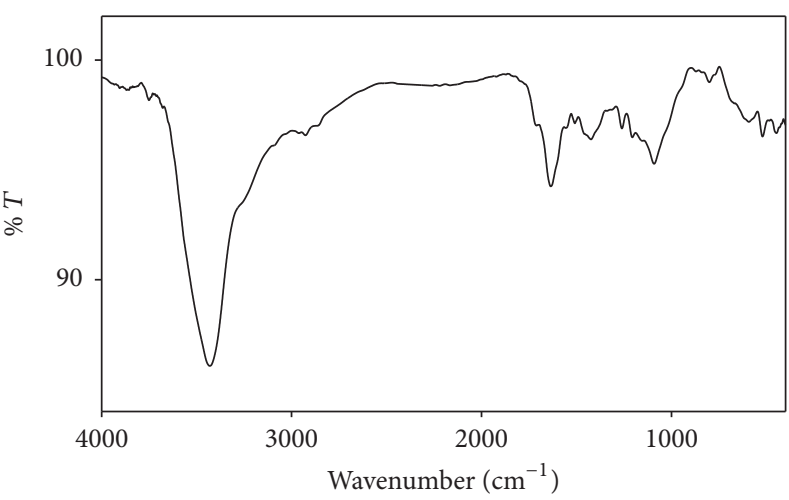

(a)

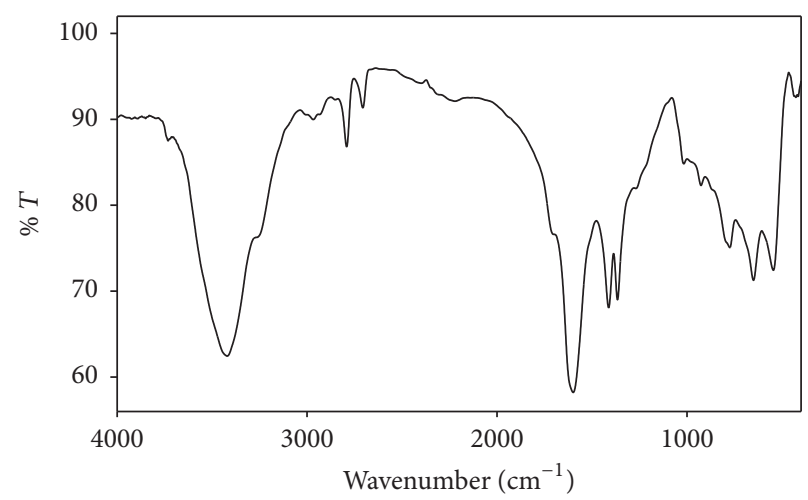

(b)

FIGURE 1: FTIR spectra of (a) chitosan (CS) and (b) CS/3-phenyl-1H-pyrazole-4-carbaldehyde.

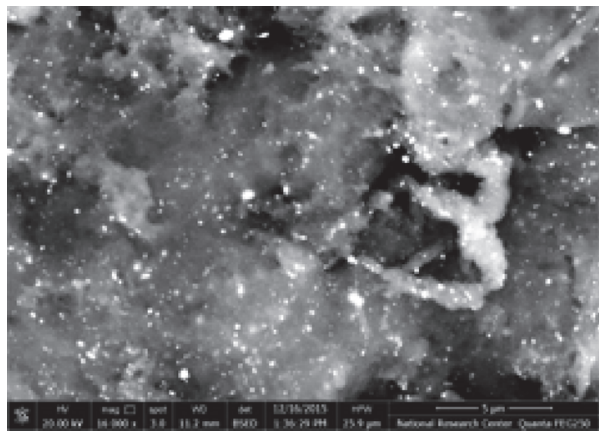

(a)

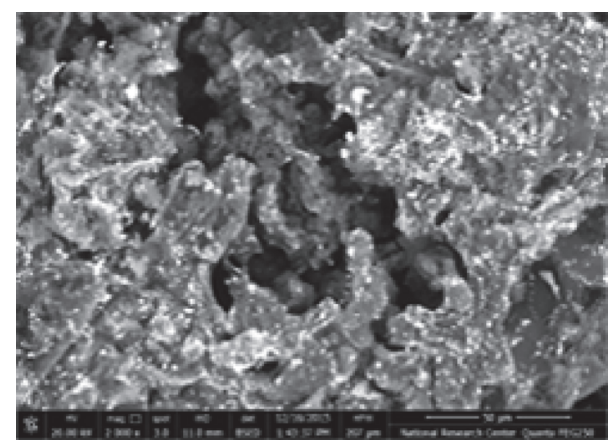

(c)

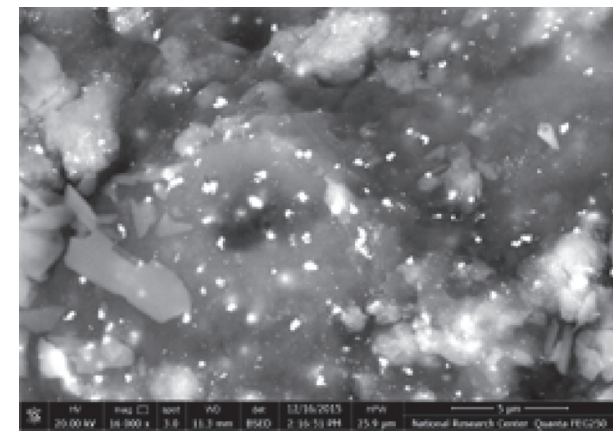

(b)

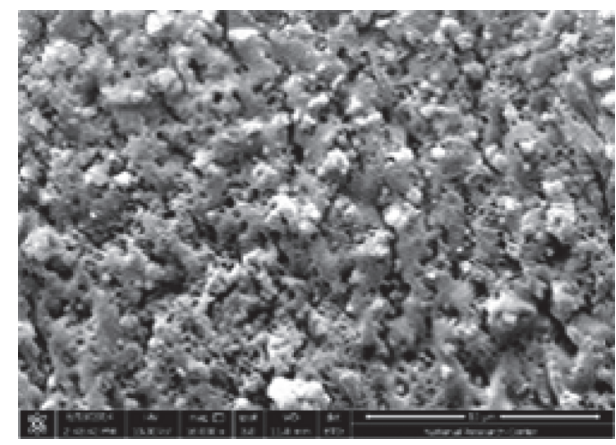

(d)

FIGURE 2: SEM of (a) CS/3-methyl-1H-pyrazole-4-carbaldehyde loaded with AgNPs; (b) CS/1,3-diphenyl-1H-pyrazole-4-carbaldehyde loaded with AgNPs; (c) CMCS/3-methyl-1H-pyrazole-4-carbaldehyde loaded with AgNPs; (d) CMCS/1,3-diphenyl-1H-pyrazole-4-carbaldehyde loaded with AgNPs.

silver nanoparticles (AgNPs) with magnification power 20,000x. It shows the distribution with acceptable dispersion of the AgNPs inside chitosan matrix with particle size from 4 to $8 \mathrm{~nm}$. This can be related to the formed complex between chitosan and $\mathrm{Ag}^{+}$leading to the formation of discrete silver nanoparticles inside chitosan matrix as a result of the activity of silver cation with $\mathrm{O}_{2}$ in the ether and $\mathrm{OH}$ groups in chitosan [46]. As noticed in Figure 3(b), the energy dispersive $\mathrm{X}$-ray spectroscopy extends more evidence about the chemical composition of the investigated sample confirming that silver nanoparticles are present in the former TEM micrograph. A similar behavior for the formation of AgNPs can be noticed in Figure 3(c) representing a TEM micrograph for the AgNPs loaded onto chitosan in the presence of 1,3-diphenyl-1H-pyrazole-4-carbaldehyde. It shows relatively normal distribution for the nanoparticles through chitosan matrix having particle size of $14-23 \mathrm{~nm}$. Some large particles can be noticed, and this may result from the 


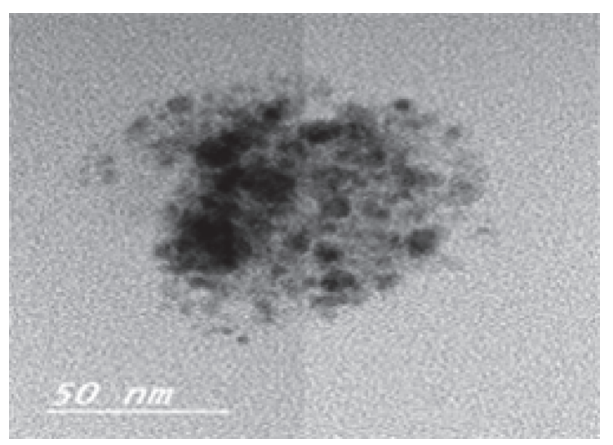

(a)

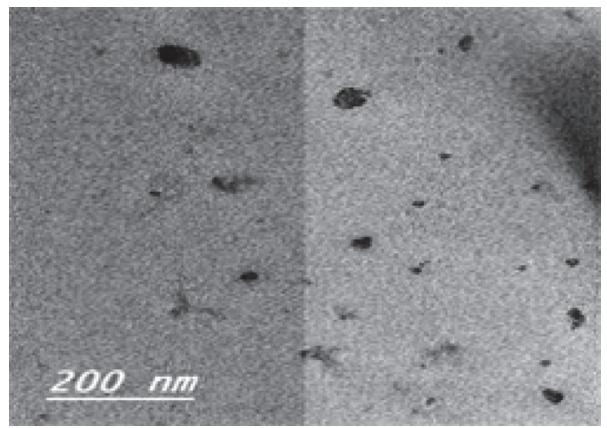

(c)

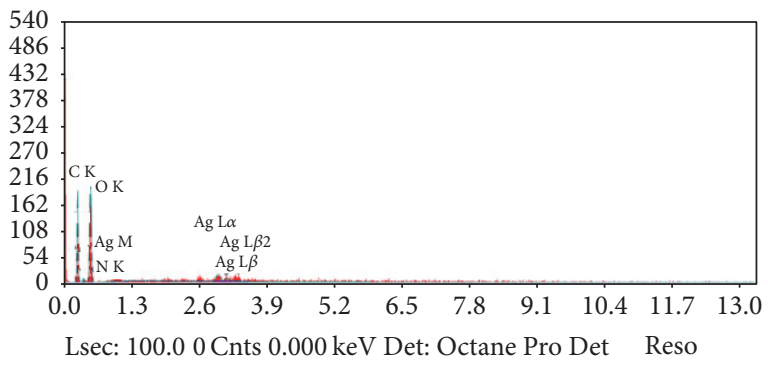

(b)

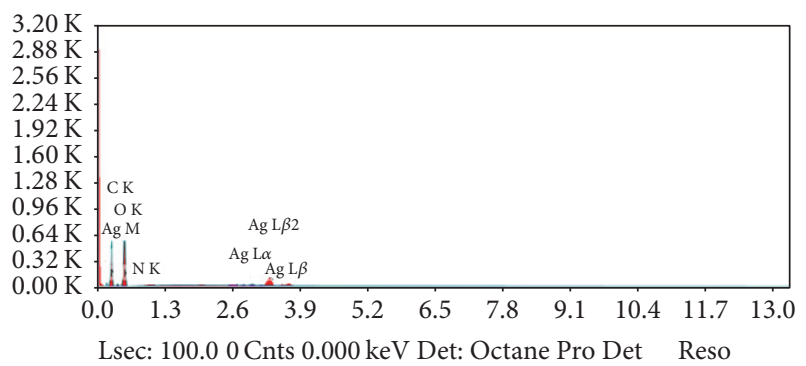

(d)

FIGURE 3: TEM of (a) CS/3-methyl-1H-pyrazole-4-carbaldehyde loaded with AgNPs. (b) EDX of CS/3-methyl-1H-pyrazole-4-carbaldehyde loaded with AgNPs. (c) TEM of CS/1,3-diphenyl-1H-pyrazole-4-carbaldehyde loaded with AgNPs. (d) EDX of CS/1,3-diphenyl-1H-pyrazole4-carbaldehyde loaded with AgNPs.

adhesion between silver nanoparticles upon reducing silver nitrate at high concentration of silver [47] but this did not affect the distribution of AgNPs in the matrix. Figure 3(d) provides additional evidence for reducing silver ions into silver nanoparticles, illustrated by EDX spectrum. It demonstrates the existence of elemental silver peaks in region of $3 \mathrm{KeV}$.

On the other hand, Figure 4(a) shows the TEM micrograph of the deposited AgNPs inside carboxymethyl chitosan in the presence of 3-methyl-1H-pyrazole-4-carbaldehyde. The spherical AgNPs in this nanocomposite showed variation in the particle size to be in the range of $13-28 \mathrm{~nm}$. The EDX pattern in Figure 4(b) displays the presence of C, O, $\mathrm{N}$, and elemental Ag absorption peaks for the main components of the tested nanocomposite. Meanwhile, upon investigating the TEM of carboxymethyl chitosan/1,3-diphenyl$1 \mathrm{H}$-pyrazole-4-carbaldehyde/AgNPs, it is observed that this nanocomposite is loaded with detached silver nanoparticles. Their nanoparticles show uniformity in the carboxymethyl chitosan matrix with sizes ranging from 5 to $11 \mathrm{~nm}$ as shown in Figure 4(c). EDX spectrum of this tested nanocomposite is illustrated in Figure 4(d), emphasizing the presence of silver nanoparticles with stronger peaks than the ones in the corresponding nanocomposite with 3-methyl-1H-pyrazole4-carbaldehyde.

3.4. Thermogravimetric Analysis (TGA). Thermogravimetric analysis is employed to inspect the thermal stability of the prepared nanocomposites as shown in Figure 5. The samples are subjected to thermal decomposition resulting in weight loss of the tested samples. At $233^{\circ} \mathrm{C}$ and $188^{\circ} \mathrm{C}$, chitosan with 3-methyl-1H-pyrazole-4-carbaldehyde and 1,3-diphenyl- $1 \mathrm{H}$ pyrazole-4-carbaldehyde, respectively, in the presence of AgNPs, demonstrate about 23-26\% weight loss. While comparing carboxymethyl chitosan with the previously mentioned aldehyde derivatives, it shows a drop at the same temperature range reaching $250^{\circ} \mathrm{C}$ but with further weight loss\% (about 35\%). This drop can be attributed to the decomposition of functional groups bearing oxygen with initial polymer degradation. The next step is thermal decomposition with depolymerization at higher temperatures till reaching $600^{\circ} \mathrm{C}$. Chitosan exhibits poor thermal stability without any noticeable improvement. On the other hand, it is noticed that carboxymethyl chitosan/1,3-diphenyl- $1 \mathrm{H}$ pyrazole-4-carbaldehyde/AgNPs shows the highest thermal stability among the tested samples starting at $260^{\circ} \mathrm{C}$ up to higher temperature degrees with conserving $64 \%$ of the sample's initial weight. The enhancement of this thermal stability can be attributed to the aldehyde derivative (1,3diphenyl-1H-pyrazole-4-carbaldehyde) supported by silver nanoparticles. This leads to slowing down the rate of thermal decomposition for carboxymethyl chitosan.

3.5. Antimicrobial Activities. Antimicrobial activities of chitosan and carboxymethyl chitosan/pyrazole Schiff-base Ag nanocomposites were examined against four pathogenic 


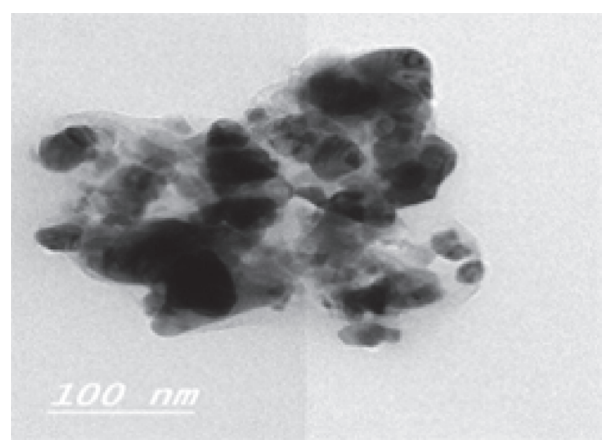

(a)

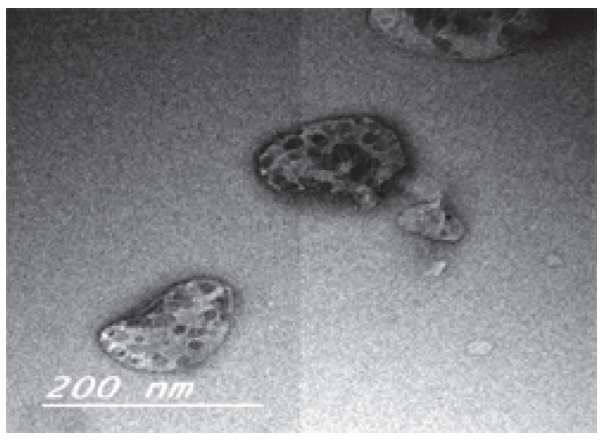

(c)

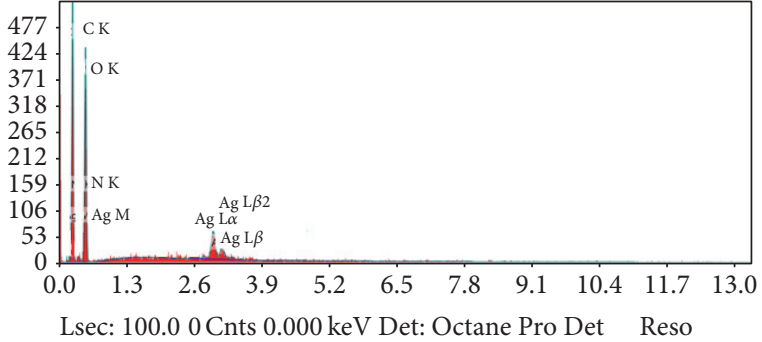

(b)

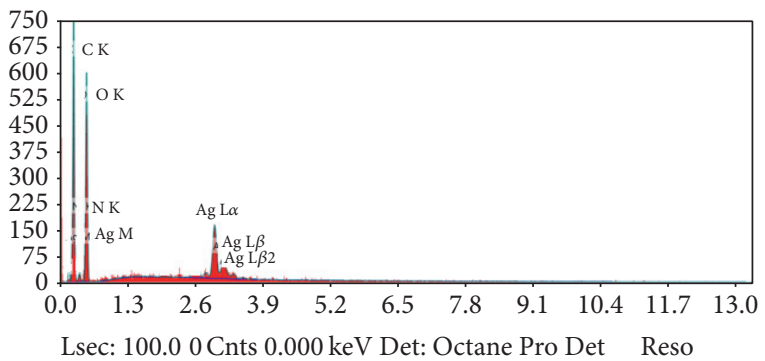

(d)

FIgurE 4: TEM of (a) CMCS/3-methyl-1H-pyrazole-4-carbaldehyde loaded with AgNPs. (b) EDX of CMCS/3-methyl-1H-pyrazole-4carbaldehyde loaded with AgNPs. (c) TEM of CMCS/1,3-diphenyl-1H-pyrazole-4-carbaldehyde loaded with AgNPs. (d) EDX of CMCS/1,3diphenyl-1H-pyrazole-4-carbaldehyde loaded with AgNPs.

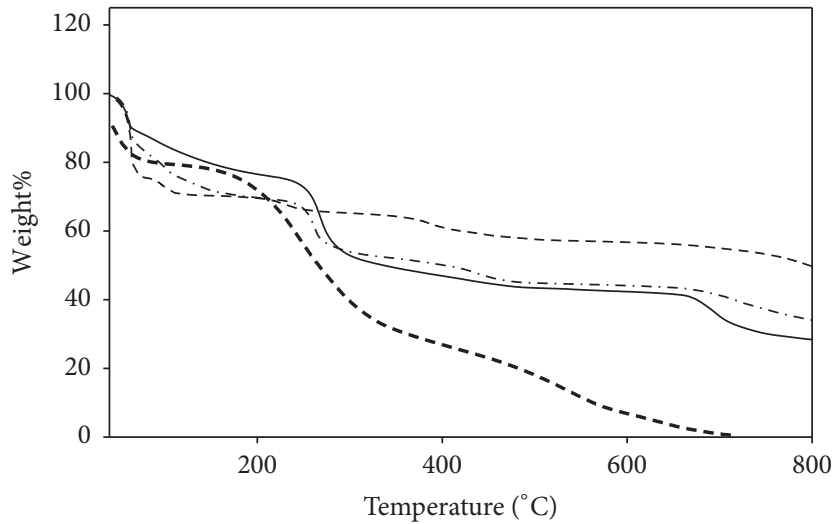

— Chitosan/3-methyl-1H-pyrazole-4-carbaldehyde/AgNPs

-. - C Chitosan/1,3-diphenyl-1H-pyrazole-4-carbaldehyde/AgNPs

- - - Carboxymethyl chitosan/3-methyl-1H-pyrazole-4carbaldehyde/AgNPs

- - Carboxymethyl chitosan/1,3-diphenyl-1H-pyrazole-4carbaldehyde/AgNPs

Figure 5: TGA of CS or CMCS/Schiff-bases loaded with AgNPs.

bacteria, two Gram +ve and two Gram - ve, in addition to a fungus. The bioactivity and sensitivity of these compounds against pathogenic microorganism were determined using well diffusion method [28] and the activity was calculated after $24 \mathrm{hr}$ for bacteria and fungi measuring the inhibition zones in $\mathrm{mm}$. The results of antibacterial and antifungal activities are represented in Tables 3 and 4, respectively. The results show a difference between all tested compounds in bioactivity on pathogenic bacterial growth. The results indicate that the prepared Schiff-bases in presence of 1 and 2 percentages by weight of $\mathrm{AgNO}_{3}$ have relatively low antibacterial activities when compared with the standard drugs. It is observed that the synthesized Schiff-base products in the presence of $3 \%$ by weight of $\mathrm{AgNO}_{3}$ are of noticeable antibacterial effect in comparison with either the applied standard or CS/CMCS. Regarding this concentration of $\mathrm{AgNO}_{3}$ (3\% weight ratio) used during Schiff-bases synthesis, it is found that most of the eight CS and CMCS/Schiffbase/Ag nanocomposites have positive effects on growth of both Gram +ve and Gram -ve bacteria producing an inhibition zone reaching $42 \mathrm{~mm}$ diameters. The two compounds 2 and 7, namely, CMCS/3-methyl-1H-pyrazole-4-carbaldehyde and $\mathrm{CS} / 1,3$-diphenyl-1H-pyrazole-4-carbaldehyde, respectively, loaded with AgNPs exhibit the highest activity on both bacterial and fungal growth [37]. Compound 2 inhibits the growth of both Gram +ve and Gram -ve bacteria. It shows inhibition zones reaching 39 and $33 \mathrm{~mm}$ with the Gram +ve bacteria, Bacillus cereus, and Staphylococcus aureus, while the inhibition zones reach 30 and $26 \mathrm{~mm}$ for the Gram -ve bacteria, Pseudomonas aeruginosa and E. coli strains, respectively. Except the very high antibacterial activity of the CS/1,3-diphenyl-1H-pyrazole-4carbaldehyde against the Gram +ve bacteria (Staphylococcus 
TABLE 3: Antibacterial activities of CS or CMCS/Schiff-base/AgNPs.

\begin{tabular}{|c|c|c|c|c|c|}
\hline Sample code & $\begin{array}{c}\mathrm{AgNO}_{3} \\
\text { (wt.\%) }\end{array}$ & $\begin{array}{l}\text { B. cereus } G+v e \\
\text { Inhibition zone } \\
(\mathrm{mm})\end{array}$ & $\begin{array}{l}\text { St. aureus } G+v e \\
\text { Inhibition zone } \\
(\mathrm{mm})\end{array}$ & $\begin{array}{l}\text { E. coli } G-v e \\
\text { Inhibition } \\
\text { zone }(\mathrm{mm})\end{array}$ & $\begin{array}{l}\text { P. aeruginosa } G-v e \\
\text { Inhibition zone } \\
(\mathrm{mm})\end{array}$ \\
\hline $\mathrm{CS}$ & 0 & 14 & 16 & 15 & 13 \\
\hline CMCS & 0 & 17 & 15 & 16 & 14 \\
\hline \multirow{3}{*}{1} & 1 & 17 & 18 & 18 & 16 \\
\hline & 2 & 20 & 22 & 21 & 17 \\
\hline & 3 & 29 & 28 & 23 & 21 \\
\hline \multirow{3}{*}{2} & 1 & 19 & 17 & 19 & 16 \\
\hline & 2 & 19 & 20 & 22 & 18 \\
\hline & 3 & 39 & 33 & 30 & 27 \\
\hline \multirow{3}{*}{3} & 1 & 15 & 16 & 18 & 15 \\
\hline & 2 & 17 & 16 & 20 & 18 \\
\hline & 3 & 31 & 30 & 22 & 26 \\
\hline \multirow{3}{*}{4} & 1 & 15 & 16 & 16 & 11 \\
\hline & 2 & 15 & 19 & 17 & 13 \\
\hline & 3 & 20 & 19 & 25 & 15 \\
\hline \multirow{3}{*}{5} & 1 & 17 & 16 & 18 & 15 \\
\hline & 2 & 20 & 18 & 20 & 18 \\
\hline & 3 & 29 & 28 & 24 & 21 \\
\hline \multirow{3}{*}{6} & 1 & 0 & 17 & 16 & 15 \\
\hline & 2 & 0 & 20 & 18 & 16 \\
\hline & 3 & 0 & 28 & 21 & 20 \\
\hline \multirow{3}{*}{7} & 1 & 17 & 18 & 17 & 16 \\
\hline & 2 & 19 & 22 & 21 & 17 \\
\hline & 3 & 31 & 42 & 25 & 23 \\
\hline \multirow{3}{*}{8} & 1 & 14 & 17 & 15 & 14 \\
\hline & 2 & 17 & 21 & 15 & 17 \\
\hline & 3 & 26 & 25 & 23 & 22 \\
\hline $\begin{array}{l}\text { Antibacterial } \\
\text { (amoxicillin) } \\
30 \mu \mathrm{g} / \mathrm{mL}\end{array}$ & 3 & 30 & 31 & 29 & 30 \\
\hline
\end{tabular}

aureus) with inhibition zone reaching $42 \mathrm{~mm}$, the CMCS derivative $\mathbf{2}$ is considered to be the most efficient compound against the two $G$ +ve and $G$-ve bacteria types. Table 4 shows the antifungal efficiency of the investigated products against Candida albicans as a fungus compared with the standard antifungal drug and with CS/CMCS. The results of antifungal activity of (CS or CMCS)/Schiff-bases indicate a high antifungal activity for compounds 1 and 2 and a moderate effect for derivatives 7 and 8 , in particular the synthesized products in the presence of 3\% by weight of $\mathrm{AgNO}_{3}$ in CS or CMCS when compared with both the standard antifungal drugs.

The high antibacterial activity of compound 2, carboxymethyl chitosan/3-methyl- $1 H$-pyrazole-4-carbaldehyde, can be elucidated upon its chemical structure. It is considered that the presence of the imine group, $-\mathrm{C}=\mathrm{N}$, of Schiff-base with its $\pi$-electrons may increase the lipophilicity of CMCS molecule leading to an easier penetration of the Schiff-base molecule into the cell membrane of the microbe. It may be followed by a disturbance in the respiration process of the microbial cell. Finally, the synthesis of proteins is blocked and further growth of bacteria will be hindered [48]. The pyrazole moiety of Schiff-base $\mathbf{2}$ may also enhance the electron density of the imine group via the electron donation properties of the methyl group in position 3. It can be postulated that the hydrogen atom attached to the pyrazole nitrogen atom which is acidic in nature and bearing a positive charge may interact with the negatively charged cell surface of the microbe by the electrostatic force leading to hindering of the microbial growth.

Furthermore, the Schiff-base derivative $\mathbf{2}$ is characterized by the presence of the carboxylic group, $-\mathrm{COOH}$, which in turn increases the hydrophilicity and the solubility of chitosan in aqueous media. Hence, this gives rise to more positive charges by its reaction with $\mathrm{NH}_{2}$ group to yield $\mathrm{NH}_{3}{ }^{+}$ 
TABLE 4: Antifungal activities of CS or CMCS/Schiff-base/AgNPs.

\begin{tabular}{|c|c|c|}
\hline Sample code & $\mathrm{AgNO}_{3}$ (wt.\%) & $\begin{array}{c}\text { Candida albicans } \\
\text { Inhibition zone } \\
(\mathrm{mm})\end{array}$ \\
\hline CS & 0 & 6 \\
\hline CMCS & 0 & 10 \\
\hline \multirow{3}{*}{1} & 1 & 8 \\
\hline & 2 & 11 \\
\hline & 3 & 20 \\
\hline \multirow{3}{*}{2} & 1 & 7 \\
\hline & 2 & 10 \\
\hline & 3 & 21 \\
\hline \multirow{3}{*}{3} & 1 & 0 \\
\hline & 2 & 0 \\
\hline & 3 & 0 \\
\hline \multirow{3}{*}{4} & 1 & 0 \\
\hline & 2 & 0 \\
\hline & 3 & 0 \\
\hline \multirow{3}{*}{5} & 1 & 0 \\
\hline & 2 & 0 \\
\hline & 3 & 11 \\
\hline \multirow{3}{*}{6} & 1 & 0 \\
\hline & 2 & 0 \\
\hline & 3 & 0 \\
\hline \multirow{3}{*}{7} & 1 & 0 \\
\hline & 2 & 8 \\
\hline & 3 & 15 \\
\hline \multirow{3}{*}{8} & 1 & 0 \\
\hline & 2 & 11 \\
\hline & 3 & 12 \\
\hline Antifungal (n & & 30 \\
\hline
\end{tabular}

with high potency to attack the microbial cell membrane to disrupt all the vital process of the microbe [49]. Another factor affecting the high antibacterial activity is the silver nanoparticles incorporated in the CMCS which is well distributed in the whole matrix as shown in Figures 2 and 3. The antibacterial effect of silver nanoparticles arises from their binding with the DNA of the microbial cell causing inhibition of bacterial replication with deactivating the functions of bacteria $[11,38]$. The AgNPs surpass the macroscaled silver due to their higher surface areas. Moreover, the biocompatibility of silver nanoparticles supports them to be utilized in some medical applications as implants, catheters, and dressing wounds $[50,51]$. The second efficient Schiffbase derivative, compound 7, namely, CS/1,3-diphenyl-1Hpyrazole-4-carbaldehyde, exhibits a conjugation by the two phenyl substituents which enhances the aromaticity of the chitosan/Schiff-base derivative. This may increase the electron density of the imine group which in turn increases the lipophilicity, as mentioned previously [48], of the investigated compound in order to penetrate the cell membrane of the microorganism and disturb its vital processes.

\section{Conclusions}

Schiff-bases of chitosan and carboxymethyl chitosan/silver nanoparticles resulting from their reaction with some pyrazole aldehydes have been synthesized, characterized, and evaluated as antimicrobial agents. The latter evaluation was against two Gram +ve bacteria (Bacillus cereus and Staphylococcus aureus) two Gram - ve bacteria (Escherichia. coli and Pseudomonas aeruginosa) and against Candida albicans as a fungus. The particle sizes of silver nanoparticles (AgNPs) were $4-28 \mathrm{~nm}$ using TEM technique. The SEM micrographs for chitosan and carboxymethyl chitosan nanocomposite with 3-methyl-1H-pyrazole-4-carbaldehyde and 1,3-diphenyl-1H-pyrazole-4-carbaldehyde loaded with silver nanoparticles showed well distribution of AgNPs on the surface of the matrix. The Schiff-bases of CMCS/3methyl-1H-pyrazole-4-carbaldehyde and CS/1,3-diphenyl$1 H$-pyrazole-4-carbaldehyde loaded with AgNPs exhibited the highest antimicrobial activities against the aforementioned bacteria and fungus. The employed substituents and AgNPs support the biological activity of the synthesized Schiff-bases.

\section{Competing Interests}

The authors declare that there is no conflict of interests regarding the publication of this paper.

\section{Acknowledgments}

The authors gratefully acknowledge the National Research Centre (NRC), Egypt, for funding this work.

\section{References}

[1] M. N. V. Ravi Kumar, "A review of chitin and chitosan applications," Reactive and Functional Polymers, vol. 46, no. 1, pp. 1-27, 2000.

[2] I. Aranaz, N. Acosta, and A. Heras, "Encapsulation of an Agrobacterium radiobacter extract containing D-hydantoinase and D-carbamoylase activities into alginate-chitosan polyelectrolyte complexes: preparation of the biocatalyst," Journal of Molecular Catalysis B: Enzymatic, vol. 58, no. 1-4, pp. 54-64, 2009.

[3] M. Dash, F. Chiellini, R. M. Ottenbrite, and E. Chiellini, "Chitosan-a versatile semi-synthetic polymer in biomedical applications," Progress in Polymer Science (Oxford), vol. 36, no. 8, pp. 981-1014, 2011.

[4] C. K. S. Pillai, W. Paul, and C. P. Sharma, "Chitin and chitosan polymers: chemistry, solubility and fiber formation," Progress in Polymer Science, vol. 34, no. 7, pp. 641-678, 2009.

[5] N. Mati-Baouche, P.-H. Elchinger, H. De Baynast, G. Pierre, C. Delattre, and P. Michaud, "Chitosan as an adhesive," European Polymer Journal, vol. 60, pp. 198-212, 2014.

[6] I. Aranaz, M. Mengíbar, R. Harris et al., "Functional characterization of chitin and chitosan," Current Chemical Biology, vol. 3, no. 2, pp. 203-230, 2009.

[7] B. K. Park and M.-M. Kim, "Applications of chitin and its derivatives in biological medicine," International Journal of Molecular Sciences, vol. 11, no. 12, pp. 5152-5164, 2010. 
[8] R. S. Jagadish, K. N. Divyashree, P. Viswanath, P. Srinivas, and B. Raj, "Preparation of N-vanillyl chitosan and 4-hydroxybenzyl chitosan and their physico-mechanical, optical, barrier, and antimicrobial properties," Carbohydrate Polymers, vol. 87, no. 1, pp. 110-116, 2012.

[9] Y.-L. Chen and C.-C. Chou, "Factors affecting the susceptibility of Staphylococcus aureus CCRC 12657 to water soluble lactose chitosan derivative," Food Microbiology, vol. 22, no. 1, pp. 29-35, 2005.

[10] S. Roller and N. Covill, "The antifungal properties of chitosan in laboratory media and apple juice," International Journal of Food Microbiology, vol. 47, no. 1-2, pp. 67-77, 1999.

[11] R.-C. Chien, M.-T. Yen, and J.-L. Mau, "Antimicrobial and antitumor activities of chitosan from shiitake stipes, compared to commercial chitosan from crab shells," Carbohydrate Polymers, vol. 138, pp. 259-264, 2016.

[12] J. Kingkaew, S. Kirdponpattara, N. Sanchavanakit, P. Pavasant, and M. Phisalaphong, "Effect of molecular weight of chitosan on antimicrobial properties and tissue compatibility of chitosanimpregnated bacterial cellulose films," Biotechnology and Bioprocess Engineering, vol. 19, no. 3, pp. 534-544, 2014.

[13] S. Jiang and C. E. Beaudoin, "Smoking prevention in china: a content analysis of an anti-smoking social media campaign," Journal of Health Communication, vol. 21, no. 7, pp. 755-764, 2016.

[14] X. Feng, K. Zheng, C. Wang, F. Chu, and Y. Chen, "Durable antibacterial cotton fabrics with chitosan based quaternary ammonium salt," Fibers and Polymers, vol. 17, no. 3, pp. 371-379, 2016.

[15] B. Lu, D. Huang, H. Zheng et al., "Preparation, characterization, and in vitro efficacy of $\mathrm{O}$-carboxymethyl chitosan conjugate of melphalan," Carbohydrate Polymers, vol. 98, no. 1, pp. 36-42, 2013.

[16] C. Brunchi, M. Bercea, S. Morariu, and M. Avadanei, "Investigations on the interactions between xanthan gum and poly(vinyl alcohol) in solid state and aqueous solutions," European Polymer Journal, vol. 84, pp. 161-172, 2016.

[17] K. B. Pandey, M. M. Mehdi, P. K. Maurya, and S. I. Rizvi, "Plasma protein oxidation and its correlation with antioxidant potential during human aging," Disease Markers, vol. 29, no. 1, pp. 31-36, 2010.

[18] R. Antony, S. T. D. Manickam, K. Saravanan, K. Karuppasamy, and S. Balakumar, "Synthesis, spectroscopic and catalytic studies of $\mathrm{Cu}(\mathrm{II}), \mathrm{Co}(\mathrm{II})$ and $\mathrm{Ni}$ (II) complexes immobilized on Schiff base modified chitosan," Journal of Molecular Structure, vol. 1050, pp. 53-60, 2013.

[19] A. B. Dos Santos, J. Traverse, F. J. Cervantes, and J. B. Van Lier, "Enhancing the electron transfer capacity and subsequent color removal in bioreactors by applying thermophilic anaerobic treatment and redox mediators," Biotechnology and Bioengineering, vol. 89, no. 1, pp. 42-52, 2005.

[20] R. Verma, N. R. Peters, M. D’Onofrio et al., "Ubistatins inhibit proteasome-dependent degradation by binding the ubiquitin chain," Science, vol. 306, no. 5693, pp. 117-120, 2004.

[21] Q. Guo, C. A. Johnson, J. B. Unger et al., "Utility of the theory of reasoned action and theory of planned behavior for predicting Chinese adolescent smoking," Addictive Behaviors, vol. 32, no. 5, pp. 1066-1081, 2007.

[22] F. Jin, D. Richmond, and Y. Wang, "The multilayer regulation of the metaphase-to-anaphase transition," Cell Cycle, vol. 8, no. 5, pp. 700-704, 2009.
[23] Z. Guo, R. Xing, S. Liu et al., "Antifungal properties of Schiff bases of chitosan, N-substituted chitosan and quaternized chitosan," Carbohydrate Research, vol. 342, no. 10, pp. 1329-1332, 2007.

[24] L. Chen, Y. Du, Z. Tian, and L. Sun, "Effect of the degree of deacetylation and the substitution of carboxymethyl chitosan on its aggregation behavior," Journal of Polymer Science, Part B: Polymer Physics, vol. 43, no. 3, pp. 296-305, 2005.

[25] H.-F. Chien, C.-P. Chen, Y.-C. Chen, P.-H. Chang, T. Tsai, and C.-T. Chen, "The use of chitosan to enhance photodynamic inactivation against Candida albicans and its drug-resistant clinical isolates," International Journal of Molecular Sciences, vol. 14, no. 4, pp. 7445-7456, 2013.

[26] Z. Liu, Y. Jiao, and Z. Zhang, "Calcium-carboxymethyl chitosan hydrogel beads for protein drug delivery system," Journal of Applied Polymer Science, vol. 103, no. 5, pp. 3164-3168, 2007.

[27] X. Yin, J. Chen, W. Yuan, Q. Lin, L. Ji, and F. Liu, "Preparation and antibacterial activity of Schiff bases from $O$-carboxymethyl chitosan and para-substituted benzaldehydes," Polymer Bulletin, vol. 68, no. 5, pp. 1215-1226, 2012.

[28] T. Baran, A. Menteş, and H. Arslan, "Synthesis and characterization of water soluble O-carboxymethyl chitosan Schiff bases and $\mathrm{Cu}(\mathrm{II})$ complexes," International Journal of Biological Macromolecules, vol. 72, pp. 94-103, 2015.

[29] M. K. Rai, S. D. Deshmukh, A. P. Ingle, and A. K. Gade, "Silver nanoparticles: the powerful nanoweapon against multidrugresistant bacteria," Journal of Applied Microbiology, vol. 112, no. 5, pp. 841-852, 2012.

[30] R. Stiufiuc, C. Iacovita, C. M. Lucaciu et al., "SERS-active silver colloids prepared by reduction of silver nitrate with short-chain polyethylene glycol," Nanoscale Research Letters, vol. 8, no. 1, article 47, 2013.

[31] A. A. El-Sayed, A. M. Khalil, M. El-Shahat, N. Y. Khaireldin, and S. T. Rabie, "Antimicrobial activity of PVC-pyrazolone-silver nanocomposites," Journal of Macromolecular Science, Part A: Pure and Applied Chemistry, vol. 53, no. 6, pp. 346-353, 2016.

[32] M. Saboktakin, X. Ye, S. J. Oh et al., "Metal-enhanced upconversion luminescence tunable through metal nanoparticlenanophosphor separation," ACS Nano, vol. 6, no. 10, pp. 87588766, 2012.

[33] V. Lazar, "Quorum sensing in biofilms-how to destroy the bacterial citadels or their cohesion/power?" Anaerobe, vol. 17, no. 6, pp. 280-285, 2011.

[34] A. Taraszkiewicz, G. Fila, M. Grinholc, and J. Nakonieczna, "Innovative strategies to overcome biofilm resistance," BioMed Research International, vol. 2013, Article ID 150653, 13 pages, 2013.

[35] G. Franci, A. Falanga, S. Galdiero et al., "Silver nanoparticles as potential antibacterial agents," Molecules, vol. 20, no. 5, pp. 8856-8874, 2015.

[36] G. Veronesi, C. Aude-Garcia, I. Kieffer et al., "Exposuredependent $\mathrm{Ag}^{+}$release from silver nanoparticles and its complexation in $\mathrm{AgS}_{2}$ sites in primary murine macrophages," Nanoscale, vol. 7, no. 16, pp. 7323-7330, 2015.

[37] B. Le Ouay and F. Stellacci, "Antibacterial activity of silver nanoparticles: a surface science insight," Nano Today, vol. 10, no. 3, pp. 339-354, 2015.

[38] K. Mijnendonckx, N. Leys, J. Mahillon, S. Silver, and R. Van Houdt, "Antimicrobial silver: uses, toxicity and potential for resistance," BioMetals, vol. 26, no. 4, pp. 609-621, 2013. 
[39] L. Upadhyaya, J. Singh, V. Agarwal, and R. P. Tewari, "Biomedical applications of carboxymethyl chitosans," Carbohydrate Polymers, vol. 91, no. 1, pp. 452-466, 2013.

[40] E. Al-Sayed, H. A. Hamid, and H. M. Abu El Einin, "Molluscicidal and antischistosomal activities of methanol extracts and isolated compounds from Eucalyptus globulus and Melaleuca styphelioides," Pharmaceutical Biology, vol. 52, no. 6, pp. 698705, 2014.

[41] O. M. Darwesh, H. Moawad, W. M. Abd El-Rahim, O. S. Barakat, and M. Z. Sedik, "Bioremediation of textile reactive blue (RB) azo dye residues in wastewater using experimental prototype bioreactor," Research Journal of Pharmaceutical, Biological and Chemical Sciences, vol. 5, no. 4, pp. 1203-1219, 2014.

[42] M. M. Gharieb, S. M. El-Sabbagh, M. A. Shalaby et al., "Production of chitosan from different species of zygomycetes and its antimicrobial activity," International Journal of Scientific and Engineering Research, vol. 6, no. 4, pp. 123-130, 2015.

[43] Z. Cimerman, N. Galic, and B. Bosner, "The Schiff bases of salicylaldehyde and aminopyridines as highly sensitive analytical reagents," Analytica Chimica Acta, vol. 343, no. 1-2, pp. 145-153, 1997.

[44] K. Kurita, S. Mori, Y. Nishiyama, and M. Harata, "N-alkylation of chitin and some characteristics of the novel derivatives," Polymer Bulletin, vol. 48, no. 2, pp. 159-166, 2002.

[45] N. A. Mohamed, M. W. Sabaa, A. H. H. El-Ghandour et al., "Preparation, characterization and antimicrobial activity of carboxymethyl chitosan schiff bases with different benzaldehyde derivatives," Journal of American Science, vol. 9, no. 3, pp. 247264, 2013.

[46] H. Huang, Q. Yuan, and X. Yang, "Preparation and characterization of metal-chitosan nanocomposites," Colloids and Surfaces B: Biointerfaces, vol. 39, no. 1-2, pp. 31-37, 2004.

[47] C. D. Saquing, J. L. Manasco, and S. A. Khan, "Electrospun nanoparticle-nanofiber composites via a one-step synthesis," Small, vol. 5, no. 8, pp. 944-951, 2009.

[48] A. Webster, M. D. Halling, and D. M. Grant, "Metal complexation of chitosan and its glutaraldehyde cross-linked derivative," Carbohydrate Research, vol. 342, no. 9, pp. 1189-1201, 2007.

[49] J. Cai, Q. Dang, C. Liu et al., "Preparation, characterization and antibacterial activity of $\mathrm{O}$-acetyl-chitosan-N-2-hydroxypropyl trimethyl ammonium chloride," International Journal of Biological Macromolecules, vol. 80, pp. 8-15, 2015.

[50] E. Abbasi, M. Milani, S. F. Aval et al., "Silver nanoparticles: synthesis methods, bio-applications and properties," Critical Reviews in Microbiology, vol. 42, no. 2, pp. 173-180, 2016.

[51] S. Agnihotri, S. Mukherji, and S. Mukherji, "Size-controlled silver nanoparticles synthesized over the range 5-100 nm using the same protocol and their antibacterial efficacy," RSC Advances, vol. 4, no. 8, pp. 3974-3983, 2014. 

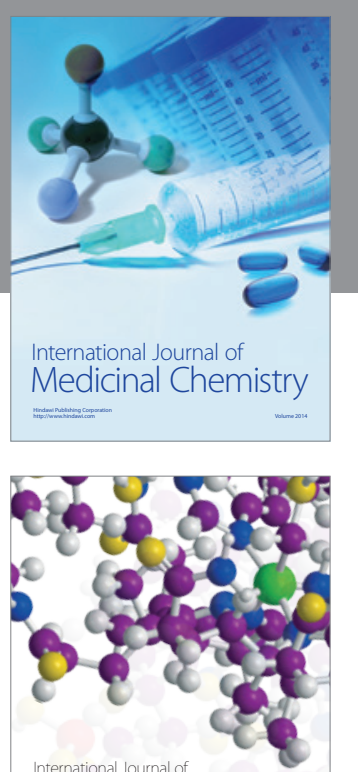

Carbohydrate Chemistry

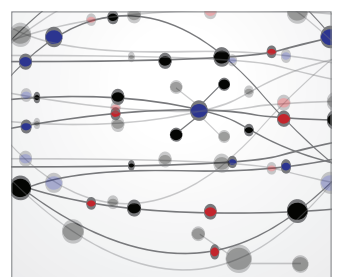

The Scientific World Journal
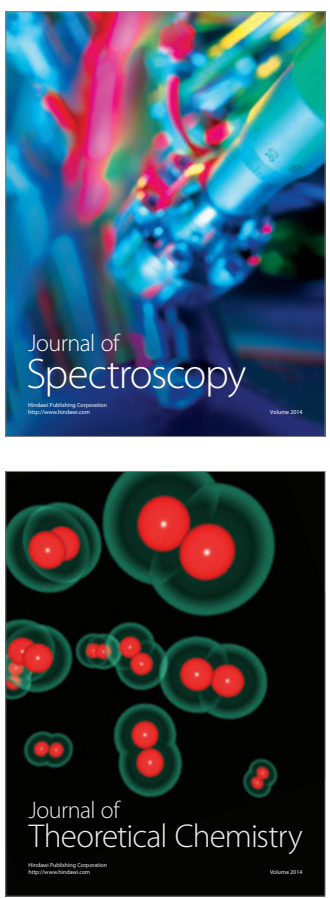
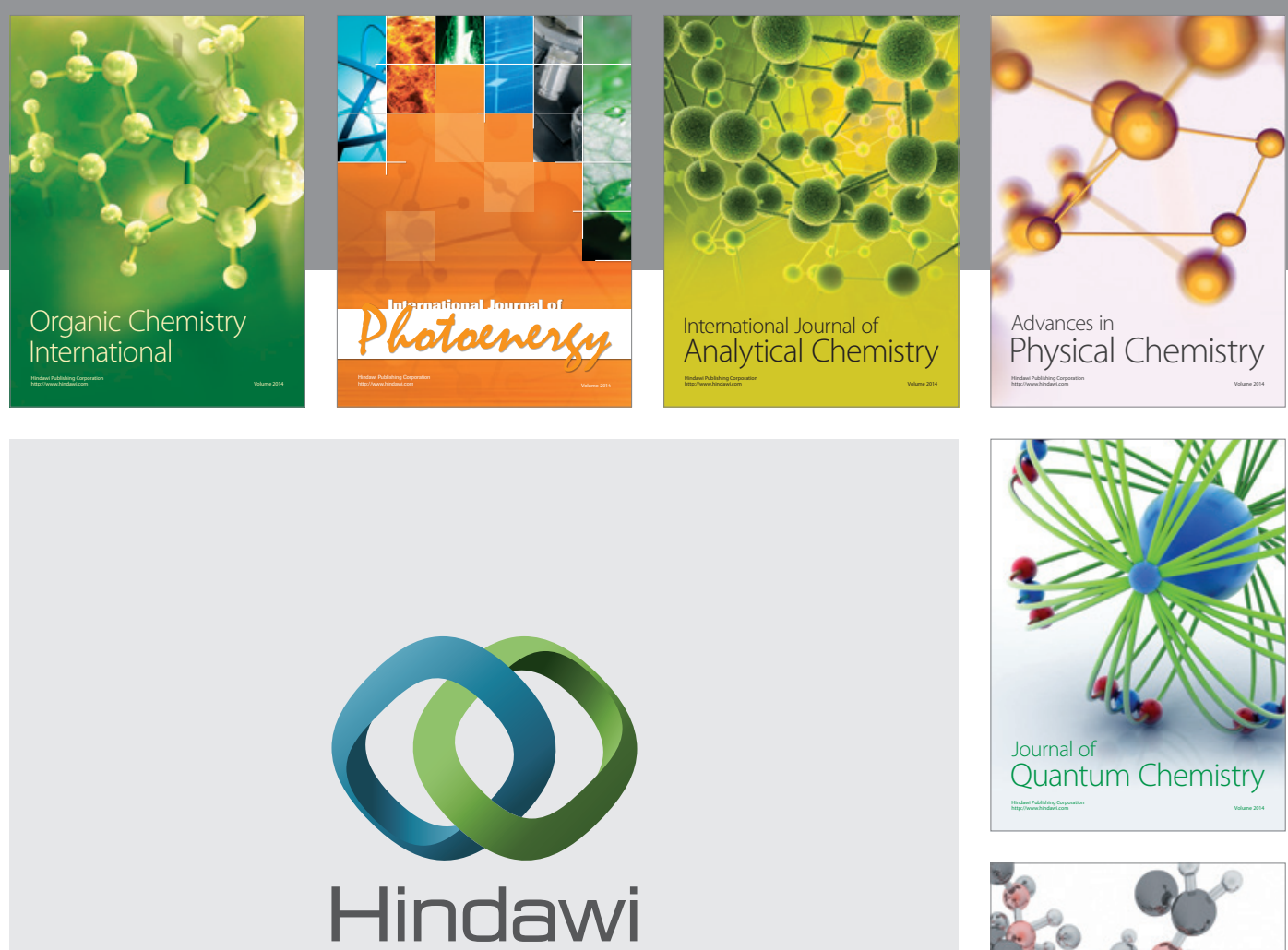

Submit your manuscripts at

https://www.hindawi.com

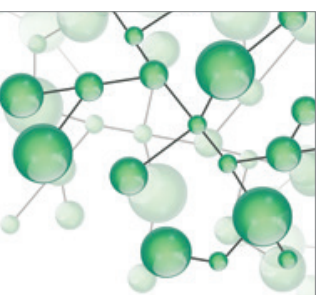

International Journal of

Inorganic Chemistry
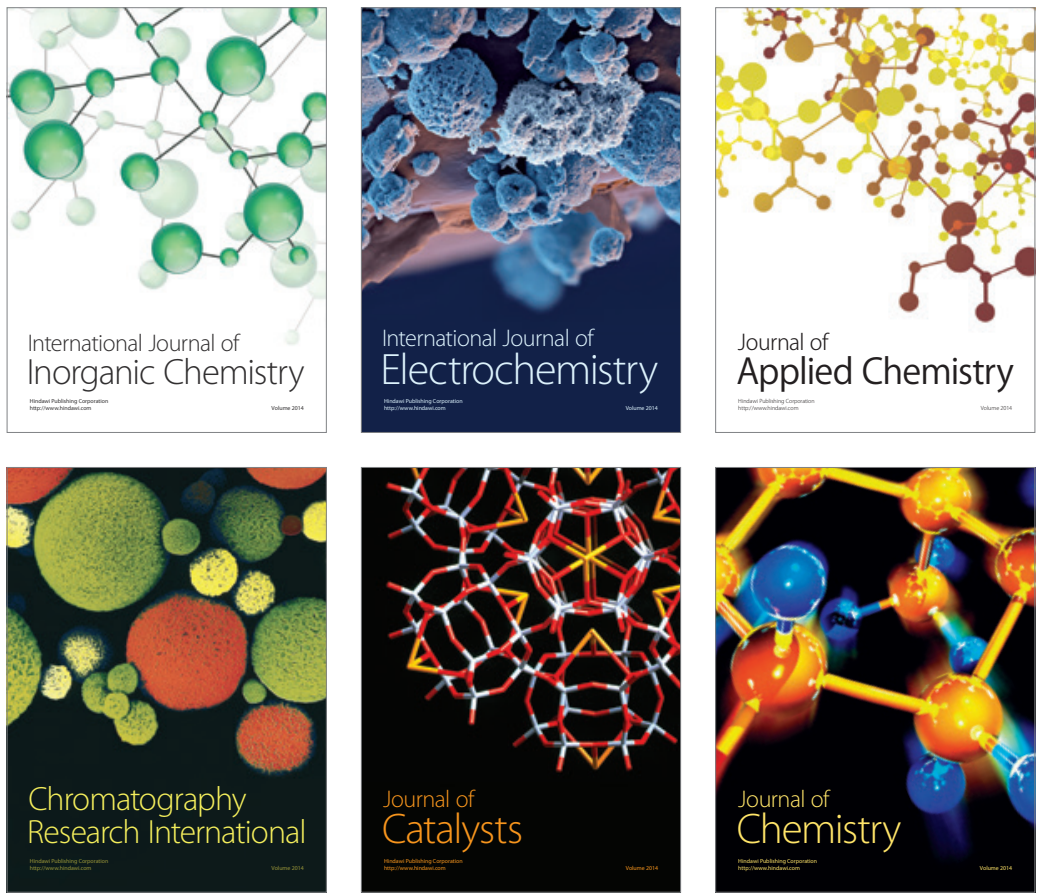

Journal of

Applied Chemistry
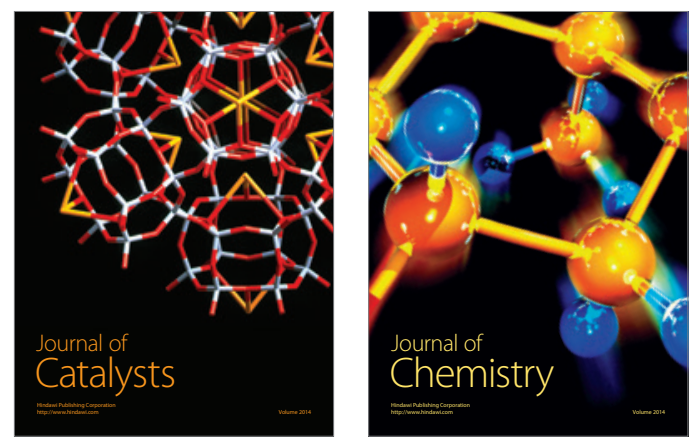
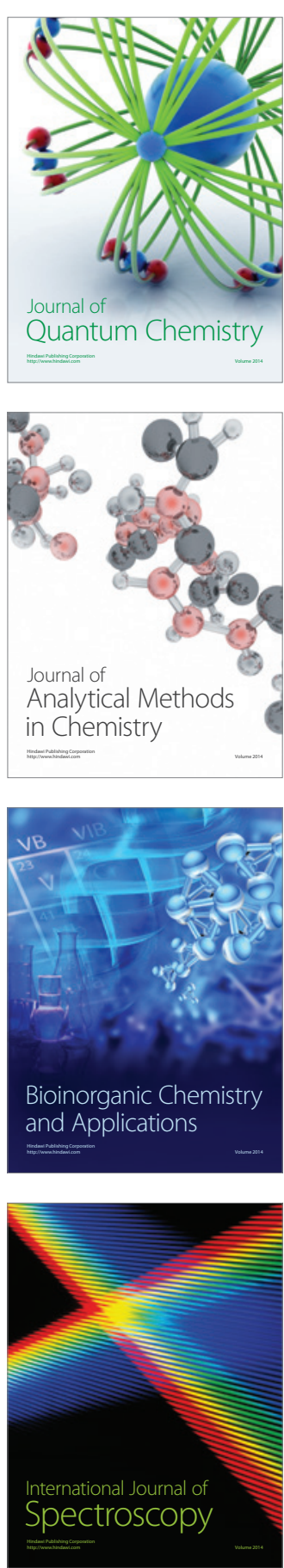